OMEGA-6 FATTY ACIDS

Linoleic

(LA) 18:2<smiles>[13CH3]</smiles>

$\gamma$-Linolenic

(GLA) 18:3

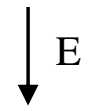

Dihomo $\gamma$-Linolenic

(DGLA) 20:3<smiles>[13CH2][AsH2]</smiles>

Arachidonic

(AA) 20:4

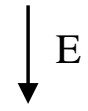

Adrenic

(DTA) 22:4

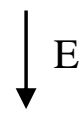

Tetracosatetraenoic

(TTA) 24:4

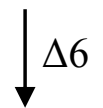

$\beta$-Tetracosapentaenoic

(BTPA) 24:5

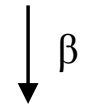

Osbond

(BDPA) 22:5

\section{OMEGA-3 FATTY ACIDS}

$\alpha$-Linolenic

(ALA) 18:3

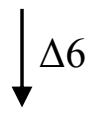

Stearidonic

(STA) 18:4

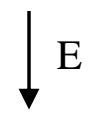

Eicosatetraenoic

(ETA) 20:4

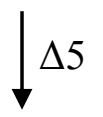

Timnodonic

(EPA) 20:5

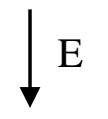

Clupanodonic

(DPA) 22:5

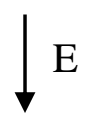

$\alpha$-Tetracosapentaenoic

(TPA) 24:5

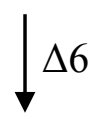

Nisinic

(THA) 24:6

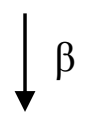

Cervonic

(DHA) 22:6 